\title{
Research on the Modular Living Walls System Based on Microclimate Adjustment in Severe Cold Areas of China
}

\author{
Ming Lu, Alin Lin* \\ School of Architecture, Harbin Institute of Technology, China
}

Copyright (C) 2015 by authors, all rights reserved. Authors agree that this article remain permanently open access under the terms of the Creative Commons Attribution License 4.0 International License

\begin{abstract}
In the severe cold areas of China, the vertical greening systems are faced with many challenges, the popularization and development are much difficult. In this paper, the differences between modular living walls technology and other greening walls techniques are studied, and the advantages of modular living walls systems in cold areas are presented. Firstly, the paper introduces the techniques of modular living walls. Secondly, it expounds the modular living walls adjusting microclimate mechanism. Finally, the key points of construct modular living walls systems in severe cold areas of China are summarized, which are expected to advice and guide technology and policy development of living walls.
\end{abstract}

Keywords Severe Cold Areas, Modular Living Walls, Microclimate

\section{Introduction}

Currently, greening systems are not only the green surfaces covered with vegetation. Greening systems, as green walls and green roofs, are used as passive cooling systems, which can improve the performance of greening systems and increase the scale of urban greening. Green walls and green roofs contribute to vegetation in the whole urban environment. Vegetation can improve the urban environment by regulating microclimate, which decreases air temperature and reduces wind speed. Vegetation absorbs solar radiation, while the effect of evapotranspiration of plants can reduce the solar radiation, showing increased humidity levels and surface temperatures. Furthermore, vegetation promotes building energy savings. Vegetation is widely used in green walls techniques.

Green walls can be divided into two parts, the green facades and the living walls (Fig.1). Green facades are based on the evergreen or deciduous climbing plants along the exterior wall of the building. Plants can grow upwards the exterior wall or take the use of continuous guides to grow vertically. However, green facades have shortcomings which are difficult to overcome. Climbing plants can easily cause damages to the exterior wall of building. Therefore, climbing plants cannot achieve certain climbing height easily, and the growth cycle of green plants is much too long. Living walls contain modular and continuous. Modular living walls consist of vegetation and planting box, artificially arranged on the vertical surfaces of building. The plant box has growth supply and can be replaced regularly. Continuous living walls are known as Vertical Gardens. The continuous living walls are the combination of modular living walls. Green facades and living walls have different characteristic, the effects of cooling and isolation of the two are quite different. In this paper, the modular living walls technique and mechanism of regulating microclimate in cold area are introduced, as well as the methods of building modular living walls.

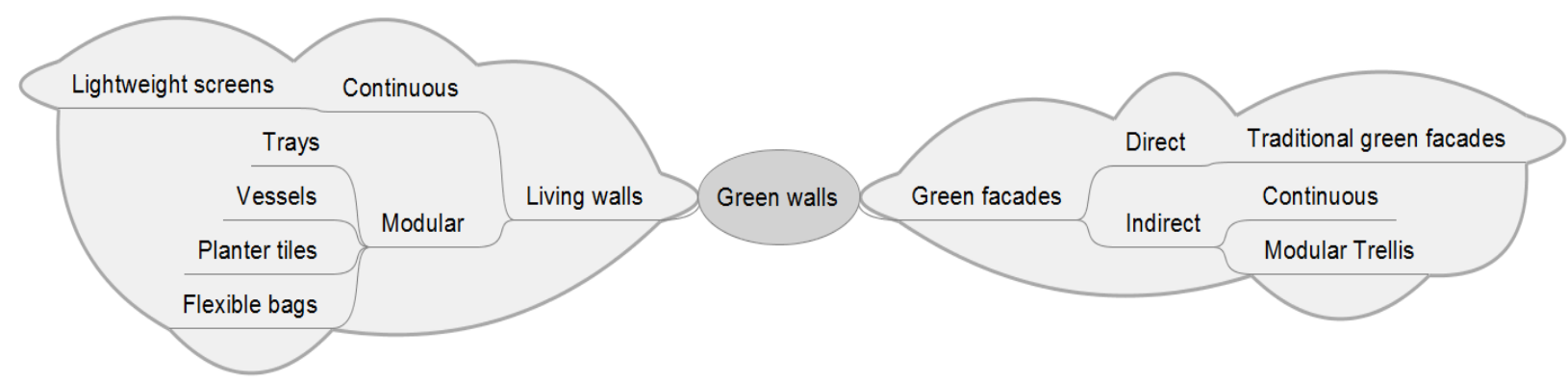

Figure 1. Different forms of green walls 


\section{Modular Living Walls}

Modular living walls are composed of vegetation and planting box, which can reduce the temperature of vertical surface of the building, and improve local thermal effects. There have researches about modular living walls in the hot regions, but rarely in the cold areas. The severe cold areas of China have long cold winter, and green plants are affected by the cold weather, much can survive the cold climate. Therefore, in the cold areas of China, the cost of building living walls is high, and it is hard to improve the microclimate comfort, especially in cold winter. For such problems, modular living walls can be suitable for cold area's climate characteristics. Therefore, modular living walls can overcome the difficult which vegetation cannot survive the cold winter, to increase the ratio of urban green space and improve the local microclimate. Moreover, modular living walls do not affect the building getting solar radiation energy in winter. Modular living walls have differences in their composition, weight and assembly.

\section{Mechanism of Modular Living Walls to Microclimate}

China's severe cold areas mainly refer to the northeast, Inner Mongolia and Northern Xinjiang, northern Tibet, Qinghai area, the coldest month average temperature is less than $-10^{\circ} \mathrm{C}$ or daily average is less than $5^{\circ} \mathrm{C}$, the number of such days more than 145; China's severe cold areas have long cold and snow covered winter. Summer air temperature and surface temperature are high, which make the summer and winter thermal comfort greatly reduced. However, the modular living wall can adjust the microclimate and improve the thermal comfort of the local areas. Atmospheric pressure, temperature, relative humidity, wind speed, wind direction, cloud cover, solar radiation are the main factors which can affect microclimate. The modular living walls regulate the microclimate mainly by affecting temperature, relative humidity, wind speed, and solar radiation. Vegetation of modular living walls affects the microclimate through regulating solar radiation to affect air temperature and vertical surface temperature, to reduce wind speed in winter and summer seasons. The main evaluation index is the air temperature and vertical surface temperature. Compared to other living walls, the modular living walls can make solar radiation balance in different seasons.

First, modular living walls can be the envelope of a building, forming an insulating layer. The thermal conductivity parameter of the isolation layer affects the environment, indirectly affects vertical surface temperature. Second, the vegetation of modular living walls can absorb, keep out and reflect part of the solar radiation. Therefore, in summer in the cold areas, the modular living walls can effectively protect the building from the solar radiation, reduce temperatures of vertical surfaces of buildings and the surroundings, regulating air temperature and relative humidity, which are the key factors affect human thermal comfort. The modular living walls use deciduous plants, after the leaves fall off naturally in winter, solar radiation can directly reach the surfaces of the buildings, which increase solar radiation heat to the buildings. In addition, the vegetation can reduce the wind speed through its luxuriant foliage. However, there have not complete standards to evaluate whether the modular living wall is good or not, especially for cold areas. Figure 2 is different forms of greening walls, (3) is modular living walls, (4) is another type of living walls which change the module.

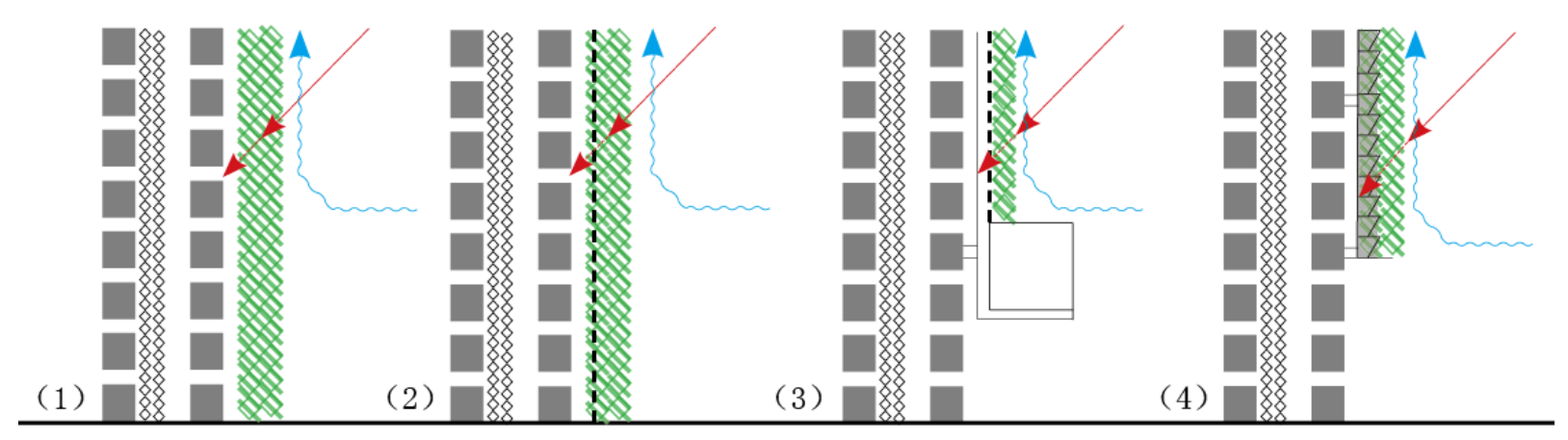

Figure2. Different forms of greening walls 


\section{Construction of Modular Living Walls in Cold Areas}

The construction of modular living walls can effectively overcome the shortcomings such as vegetation's climbing height is not certain and growth is slow. The arrangement and combination of the modules are quite fast, effective and convenient. Vegetation is not subject to the constraints of vertical climbing, and planting boxes can move indoors in winter, which could reduce the cost of building the modular living walls. The studies on the modular living walls need quantification. Quantify the impacts of vegetation on the microclimate of the surrounding environment. Many multi-disciplinary, cross discipline research works in cold areas have been studied. On the architecture function and architectural spaces, such as city streets, parks, commercial block, public space, residential areas; on the vegetation, the studies include configuration, plant species. At present, in the cold areas of China, the construction of scientific and reasonable modular living walls still has a lot of work to do.

Firstly, the construction of modular living walls needs scientific and quantitative research. The design of modular living walls rely on computer simulation, for the development of modular living walls, physical models are established to analyze microclimate. The models need for modification. Simulation and design are inseparable. In severe cold areas, the evaluation index of modular living walls is not comprehensive enough, lack of snow covered on the construction effect of module in winter. It is necessary to establish a complete living walls evaluation system, analyze a number of parameters as multidisciplinary ways, this is the necessary access to get the modular living walls evaluation index, and the index can be through statistical methods for integration, according to the actual need to use. These indexes can form the standards, and provide a standard method for the measurement and simulation of the living walls in cold areas. A database is needed to record data of research and simulation, unified research method. It is better for the comparison and reference of the modular living walls system in the cold areas among the world.

Secondly, the construction of modular living walls requires the support of the plant database system. Figure 3 is the vegetation of modular living wall suitable for severe cold areas of China. The main advantages of modular living walls in the severe cold areas are choose suitable plants which adapted to the cold climate, according to the ratio of plant species and reasonable selection module and the soil and water in module, maximizes the performance of the living walls. In addition, vegetation of modular living walls can move indoor in winter, which expanded the choices of the greening plants. If vegetation is deciduous plants, the module on the vertical surfaces of buildings should be considered in winter, the snow cover in planting box, formed snow protection layer on the vertical surfaces of buildings, and may have influences on thermal effects. To sum up, the construction of modular living walls needs to establish a complete plant database system, elaborated performances of vegetation. These works need systematic.

Finally, the construction of modular living walls requires the guidance and protection of policy. At present, the modular living walls in cold areas are still under construction. The design methods are of great significance for the popularization of modular living walls in cold areas, together with the building functions, open spaces and vegetation species, based on the temperature and humidity, wind and solar radiation. The related technical parameters which can improve the microclimate and human thermal comfort should be studied. In addition, learning the reference cases of modular living walls in other climatic regions is quite necessary. Make simple and practical modular living walls could reduce the cost and increase application. Popularize concepts and benefits of modular living walls are quite important, the citizens need to understand modular living wall's significance in improving the urban microclimate.

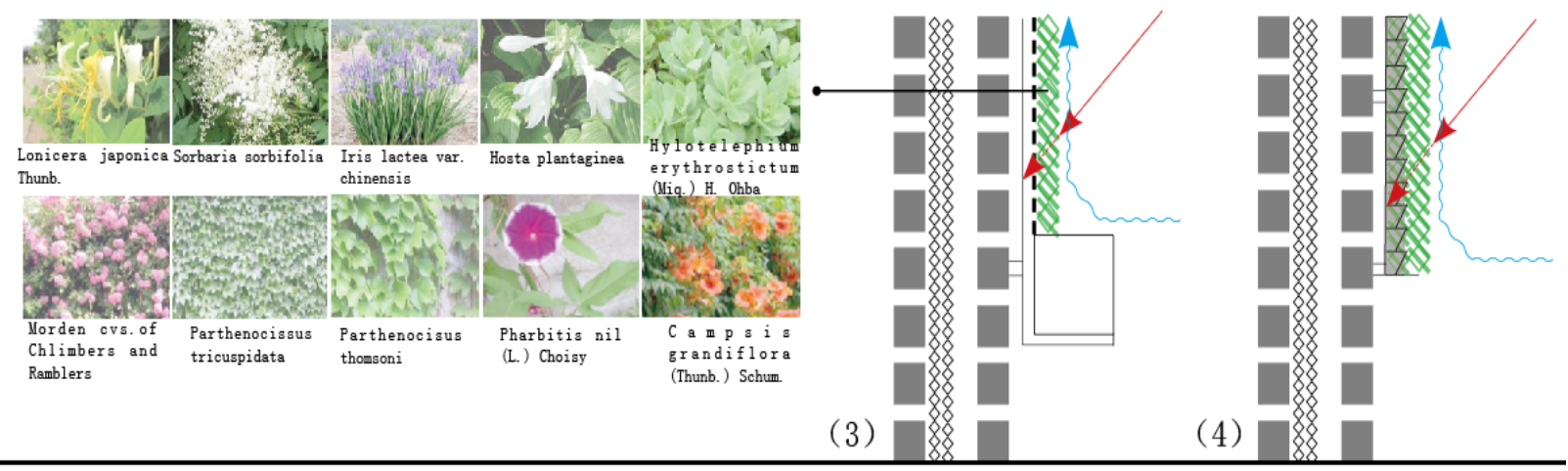

Figure 3. Vegetation of modular living wall suitable for severe cold areas of China 


\section{Conclusions}

Modular living walls can balance the solar radiation both in winter and summer, through choosing the vegetation in the severe cold areas of China. The mechanism of modular living walls to improve microclimate has stated in the paper. Although a lot of theoretical researches about living walls in severe cold areas have already begun, but the practice works on the design and policy guidance are still lack of scientific definition. For example, how to overcome climatic conditions establish a system of modular living wall mode, how to develop evaluation methods in severe cold areas of China, these also require a lot of research works.

\section{Acknowledgements}

The study was financed by National Natural Science Foundation of China for the major project "Adjustment principle and design method of the city micro-climate for severe cold areas" (No. 51438005).

\section{REFERENCES}

[1] Marc Ottelé, Katia Perini, A.L.A. Fraaij, E.M. Haas, R. Raiteri. Comparative life cycle analysis for green facades and living wall systems. Energy and Buildings, 43, (2011), 34193429 .

[2] Maria Manso, João Castro-Gomes. Green wall systems: A review of their characteristics. Renewable and Sustainable Energy Reviews, 41, (2015), 863-871.

[3] C. Bolton, M.A. Rahman, D. Armson, A.R. Ennos. Effectiveness of an ivy covering at insulating a building against the cold in Manchester, U.K: A preliminary investigation. Building and Environment, 80, (2014), 32-35.

[4] Perini K, Rosasco P. Cost-benefit analysis for green facades and living wall systems[J]. Building and Environment, 2013, 70: $110-121$.

[5] Haggag M, Hassan A, Elmasry S. Experimental study on reduced heat gain through green facades in a high heat load climate[J]. Energy and Buildings, 2014, 82: 668-674.

[6] Alexandri E, Jones P. Temperature decreases in an urban canyon due to green walls and green roofs in diverse climates[J]. Building and Environment, 2008, 43: 480-493. 